\title{
Biological Behaviour of Craniopharyngiomas
}

\author{
Juan Pedro Martinez-Barbera ${ }^{a}$ Cynthia Lilian Andoniadou ${ }^{b}$ \\ ${ }^{a}$ Developmental Biology and Cancer, Birth Defect Research Centre, GOS Institute of Child Health, University College \\ London, London, UK; ${ }^{\mathrm{b}}$ Centre for Craniofacial and Regenerative Biology, Faculty of Dental, Oral, and Craniofacial \\ Sciences, King's College London, London, UK
}

\section{Keywords}

Adamantinomatous craniopharyngioma - BRAF-V600E .

CTNNB1 · Papillary craniopharyngioma

\begin{abstract}
Jakob Erdheim (1874-1937) first described craniopharyngiomas (CPs) as "hypophyseal duct tumours" and postulated the existence of two tumour types based on their histological features: (1) an aggressive type showing similarities to adamantinomas (tumours of the jaw) and (2) a more benign form characterised by the presence of papillary structures. More than a century later, these initial observations have been confirmed; based on their distinct genetic, epigenetic, and histological features, the WHO classifies CPs into two types: adamantinomatous CPs (ACPs) and papillary CPs (PCPs). Considerable knowledge has been generated on the biology of CPs in the last 20 years. Mutations in CTNNB1 (encoding $\beta$-catenin) are prevalent in $A C P$, whilst PCPs frequently harbour mutations in BRAF (p.BRAF-V600E). The consequence of these mutations is the activation of either the WNT/ $\beta$-catenin (ACP) or the MAPK/ERK (PCP) pathway. Murine models support a critical role for these mutations in tumour formation and have provided important insights into tumour pathogenesis, mostly in ACP. A critical role for cel-
\end{abstract}

lular senescence has been uncovered in murine models of ACP with relevance to human tumours. Several gene profiling studies of human and murine ACP tumours have identified potential targetable pathways, and novel therapeutic agents are being used in clinical and pre-clinical research, in some cases with excellent results. In this review, we will present the accumulated knowledge on the biological features of these tumours and summarise how these advances are being translated into potential novel treatments.

c) 2020 S. Karger AG, Basel

\section{Introduction}

Craniopharyngiomas (CPs) are benign tumours (WHO grade 1) that develop in the sellar region, which is an anatomical structure limited ventrally by the cranial base, dorsally by the dorsum sellae (with the suprasellar cistern and optic chiasm immediately superior to this), laterally by the cavernous sinuses and carotid arteries, and caudally by the brain stem. CPs were first described by the Viennese pathologist Jakob Erdheim in a 200-pagelong report published in 1904 [1-3]. Despite their benign histological nature, CPs can be clinically challenging due to their location and their tendency to invade surround- karger@karger.com

(c) 2020 (c) 2020 S. Karger AG, Basel

www.karger.com/nen

Karger ${ }^{\prime}=$
Juan Pedro Martinez-Barbera

Developmental Biology and Cancer, Birth Defect Research Centre

UCL GOS Institute of Child Health, 30 Guilford Street

London, WC1N 1EH (UK)

j.martinez-barbera@ucl.ac.uk 
ing structures such as the pituitary gland, hypothalamus, and visual pathways. Current treatments are surgery followed by radiotherapy, but these modalities are not always curative and can often contribute to further damage. Overall, CPs are associated with a high degree of morbidity, leading to poor quality of life and increased mortality rate on long-term follow-up [4].

There are two types of CPs: (i) The adamantinomatous form of CP (ACP) is the most frequent pituitary tumour in children and shows a bimodal peak of distribution (5-15 years in the childhood-onset ACP and 45-60 years in the adult-onset ACP); (ii) The papillary form (PCP) is mostly an adult tumour (peak at $40-45$ years). Research from the last 10 years has demonstrated that these two tumour types represent distinct identities each with specific genetic, epigenetic, and pathological features. In this minireview, we will discuss the main features that differentiate ACP and PCP, and elaborate how the biological differences have helped identify novel targeted treatments. Further readings are recommended to cover more detailed pathological and clinical descriptions [4-11].

\section{Pathology of Craniopharyngiomas}

ACPs are tumours that usually contain solid as well as cystic components. The solid part of the tumour comprises epithelial tumour cells, which are highly heterogeneous and include the palisading epithelium, stellate reticulum, and groups of cells forming whorl-like structures [12] (Fig. 1). The palisading epithelium and stellate reticulum form finger-like protrusions near the invasive front, which usually contain a string of cell whorls inside [13]. Surrounding the epithelial tumour, ACPs often contain glial reactive tissue, mostly comprising astrocytes and immune cells. The proportions of tumour epithelium and glial reactive tissue can vary considerably between ACP samples: for instance, some tumour samples may contain mostly tumour epithelium with little or no reactive glial tissue, whilst others may be comprised mostly of glial tissue with little epithelial component [14]. Other histopathological features include calcification, which can be observed by computerised tomography scans, and the presence of nodules of wet keratin (containing cells without visible nuclei). Both of these features help establish a diagnosis of ACP. ACP tumours can hold one or several cysts filled with a dark fluid commonly referred to as machine oil, which is rich in lipids and inflammatory mediators.
PCPs are solid epithelial tumours, characterised by the presence of a well-differentiated non-keratinising squamous epithelium supported by fibrovascular cores (Fig. 1). Fibrovascular cores are tubular structures that contain stroma and blood vessels, lined by a well-defined pseudostratified epithelium (Fig. 1). PCPs are rarely cystic and do not show calcification.

\section{Genetic and Epigenetic Alterations in Craniopharyngiomas}

ACP

Mutations in CTNNB1 were first reported in ACPs by Sekine et al. [15] in 2002. This finding has been subsequently recapitulated in many independent studies, and CTNNB1 mutations have been identified in $16-100 \%$ of the tumours analysed [16]. These mutations, which affect mostly the amino acids encoded by exon 3 of CTNNB1, are predicted to result in the expression of a degradationresistant form of the protein leading to the activation of the WNT/ $\beta$-catenin pathway [17]. Failure to identify the mutation in all ACP samples has led to the speculation that other genetic mutations may underlie ACP tumourigenesis. Indeed, coexisting mutations in BRAF (V600E) and CTNNB1 (T41I) have been identified in $2 \mathrm{ACP}$ tumours [18]. Sanger sequencing of specific cell populations has furthered controversy on whether the mutations are clonal or present only in some but not all the epithelial tumour cells $[15,19,20]$. Recently, laser capture microdissection was combined with tagged-amplicon deep sequencing, an ultrasensitive approach that detects very low mutant allelic frequencies, to screen $22 \mathrm{ACP}$ tumour samples. CTNNB1 mutations were identified in all samples including those with very low mutant allelic frequencies [21]. These data suggest that failure to identify CTNNB1 mutations in a low proportion of ACP tumours may be due to the lower sensitivity of the sequencing technology used in previous studies (e.g., Sanger sequencing, single-strand conformation polymorphism analysis, exome sequencing, and targeted next-generation sequencing). Therefore, if there are other oncogenic mutations in human ACPs, these are likely to be rare compared with CTNNB1 mutations.

Murine studies have confirmed that CTNNB1 mutations are oncogenic drivers, i.e., capable of initiating and sustaining tumourigenesis. The expression of a functionally equivalent form of stabilised $\beta$-catenin in either pituitary embryonic precursors or SOX2+ adult stem cells results in the formation of ACP-like tumours in mice [22, 




Fig. 1. Histological features of human craniopharyngioma. Top: Haematoxylin \& eosin (HE) staining and immunohistochemistry against $\beta$-catenin on human ACP histological sections. Human ACPs are heterogenous tumours containing tumour epithelia (TE) and glial reactive tissue (GRT). Closer examination of the tumour epithelia identifies cells grouped in whorl-like structures (WL), which are surrounded by large cells with empty cytoplasm (stellate reticulum, SR) and a pseudostratified palisading epithelial layer (PE). Immunohistochemistry shows that nucleo-cytoplasmic ac-

23]. These tumours resemble some of the histological and radiological features of human ACP [24], but do not calcify or show wet keratin. A common characteristic in mouse and human ACP is that nucleocytoplasmic accumulation of $\beta$-catenin occurs only in sporadic cells, frequently forming cell clusters that overlap with the epithelial whorls previously described or dispersed throughout the tumour as single cells (Fig. 1) [25]. The reason why protein accumulation occurs only in a small cell fraction, despite the presence of the CTNNB1 mutation throughout the tumour, remains unknown. These cell clusters, showing nucleocytoplasmic accumulation of $\beta$-catenin, are not present in PCP or any other pituitary tumour [26]. cumulation of $\beta$-catenin occurs mostly in the WL. Bottom: HE staining and immunohistochemistry against BRAF-V600E of human PCP histological sections. Human PCPs contain large sheets of squamous epithelia (SE) surrounded by fibrovascular cores (FC), which provide support to the tumour cells. FCs are lined by a pseudostratified epithelium (PSE). Immunohistochemistry shows the expression of BRAF-V600E throughout the squamous epithelium, but not in the fibrovascular cores. Scale bar, $200 \mu \mathrm{m}$.

As well as histologically, gene expression profiling has demonstrated that mouse and human clusters are equivalent molecular structures [14]. Moreover, the pattern of gene expression in the clusters resembles the enamel knot, a critical signalling centre that controls epithelial and mesenchymal interactions during tooth development. These similar molecular signatures have provided a molecular paradigm that explains the histological similarities between ACP and tooth development and tumours of the teeth, which have been reported for over a century [2,27].

ACPs and PCPs have a low mutation rate (non-synonymous mutation rate of 0.9 per $\mathrm{Mb}$ ), which is expected in benign grade I tumours [28]. They have stable genomes 
and gains or losses of large chromosomal regions are rare. In one study, more focal losses and gains of unknown function were identified [29]. The methylomes are different between ACPs and PCPs, a feature that facilitates molecular diagnosis $[30,31]$, but the functional significance of distinct epigenetic landscapes remains unknown.

\section{PCP}

PCPs are likely to be driven by mutations in $B R A F$, specifically p.BRAF-V600E. This mutation has been identified in the vast majority of PCP tumours analysed and the expression of the mutant protein confirmed by immunohistochemistry using an anti-BRAF-V600E antibody (Fig. 1) [28, 32]. Although this mutation is predicted to result in the activation of the MAPK/ERK pathway in all tumour cells, immunohistochemistry against phospho-ERK1/2 (pERK1/2), a read-out of the active MAPK/ ERK pathway, has revealed that only a small proportion of epithelial cells lining the fibrovascular cores activate this pathway, despite the expression of BRAF-V600E throughout the tumour [32]. In this study, thesepERK1/2+ cells were shown to express the pituitary stem/progenitor markers SOX2 and SOX9, suggesting that these lining cells may represent tumour stem cells. Moreover, the vast majority of the Ki67+ proliferative cells are contained within the SOX2/SOX9+ compartment around the fibrovascular cores. Mouse models expressing the p.BRAF$V 600 E$ mutation have been generated, but perinatal lethality has prevented assessment of the potential tumourigenic effect [32]. Nonetheless, close examination of these murine models has revealed that the expression of this oncogenic driver in early pituitary precursors leads to the expansion of SOX2/SOX9+ stem cells, which are highly proliferative and show impaired differentiation. Together, studies in the mouse and humans suggest a likely tumourigenic mechanism, by which the activation of the MAPK/ERK pathway within SOX2/SOX9 stem cells may lead to tumour formation.

\section{Cellular Senescence in ACP Tumourigenesis}

Molecular profiling and immunohistochemistry analyses have revealed that the cluster cells in both mouse and human ACPs contain senescent cells. Senescence is defined as a cellular state that is characterised by a permanent cell cycle arrest due to the expression of cell cycle inhibitors (e.g., p16 and p21) [33, 34]. Senescence is induced by several stressors that cause DNA damage, among them radiotherapy, chemotherapy, and oncogen- ic signalling. Despite the fact that senescent cells are unable to re-enter the cell cycle (except if cell cycle arrest pathways are inactivated by genetic or epigenetic mechanisms), these cells are metabolically very active and secrete a plethora of growth factors and inflammatory mediators referred to as the senescence-associated secretory phenotype (SASP) [35]. A bulk of research has shown that senescent cells underlie several ageing-related diseases or even contribute to organismal ageing through SASP activities [36]. In cancer, senescent cells are a double-edged sword that can prevent expansion of cells harbouring DNA damage autonomously but also promote tumour expansion and progression to malignancy in a cell nonautonomous manner [35, 37].

Studies in ACP mouse models have provided insights into the role of senescent cluster cells in initiating tumour formation. Initial experiments, in which SOX2+ pituitary stem cells were targeted to express oncogenic $\beta$-catenin and simultaneously a fluorescent reporter (e.g., yellow fluorescent protein) demonstrated that these stem cells are the cell of origin of the $\beta$-cateninaccumulating cell clusters, but not of the tumours, which are derived from a different cell lineage [22]. Based on these results, a model of paracrine tumourigenesis was proposed, in which the cluster cells may be able to induce tumour formation in a paracrine manner, but the underpinning mechanisms were not understood (Fig. 2). More recently, it has been shown that mouse and human clusters contain senescent cells with an activated SASP, and that the attenuation of the senescent/SASP response in murine cluster cells, either genetically or in aged mice, result in a significant reduction in tumour-inducing potential $[38,39]$.

\section{From Biology to Novel Therapies}

The significant increase in knowledge of tumour biology that has accumulated over the last few years has led to the identification of novel targetable pathways in both PCP and ACP. The presence of p.BRAF-V600E mutations in PCP patients has provided a molecular rationale for the use of MAPK/ERK pathway inhibitors in these patients. Although the pERK1/2+ cells are just a minority of the tumour cells in PCP tumours [32], the inhibition of the MAPK/ERK pathway using BRAF-V600E or MEK inhibitors, alone or in combination, has given excellent results in patients [40,41]. The success in these small studies has led to a clinical trial in BRAF-V600E-positive PCP patients using a combination of vemurafenib (BRAF-V60E 


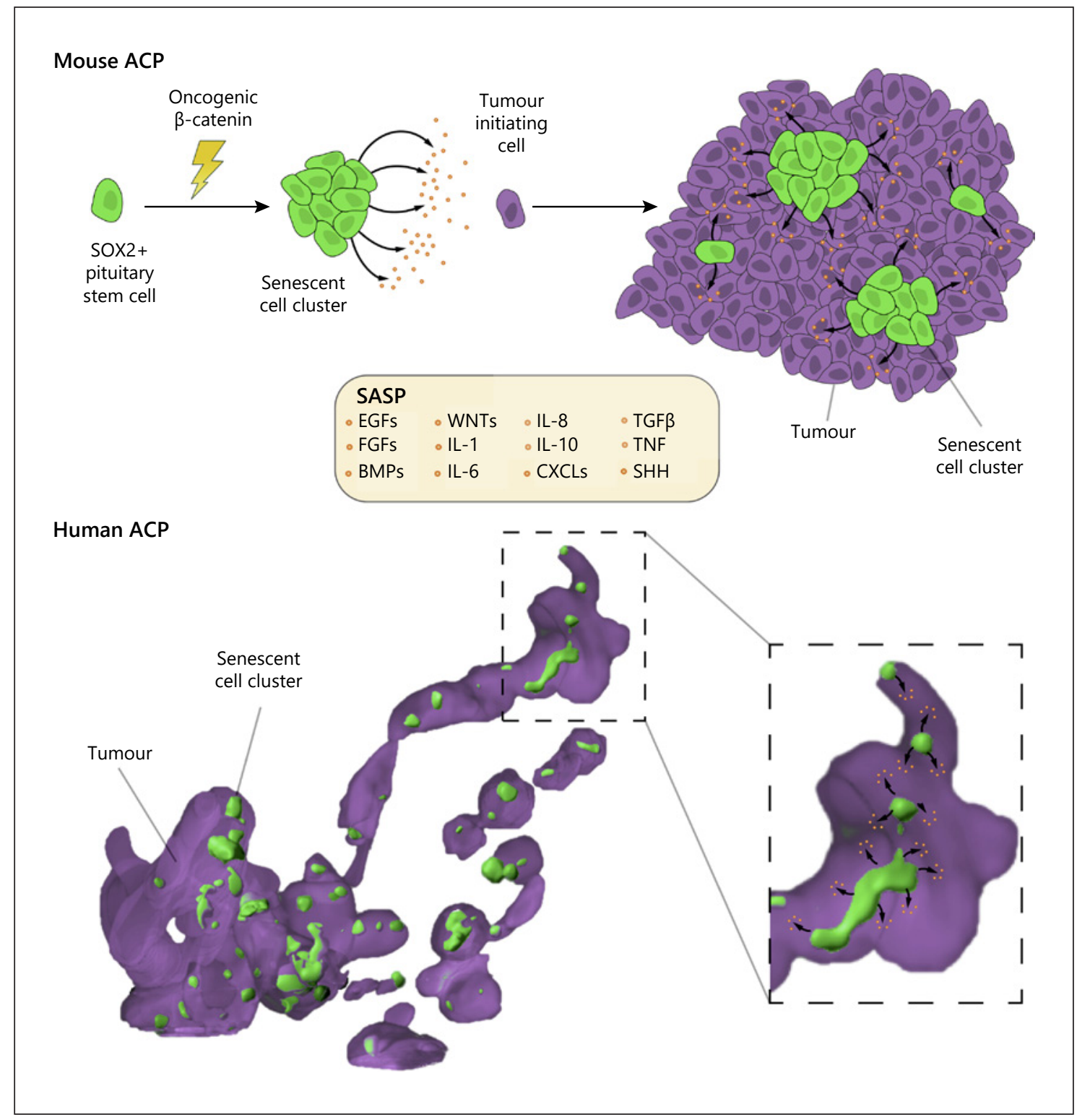

Fig. 2. Schematic showing a working model for the role of the $\beta$-catenin-accumulating cell clusters in mouse and human ACPs. Top: Expression of oncogenic $\beta$-catenin in SOX $2+$ pituitary stem cells (both embryonic and postnatal) results in the formation of $\beta$-catenin-accumulating cell clusters, which contain senescent cells (oncogene-induced senescence). Senescent cluster cells activate a senescence-associated secretory phenotype (SASP), which leads to the synthesis and secretion of a plethora of active peptides, some of which are included in the box. The persistent activity of the SASP factors on surrounding cells eventually causes cell transformation of a cell not of the SOX2 cell lineage (purple cell) and subsequent tumour development in a paracrine manner. Bottom: The human tumour depicted in the schematic derives from a threedimensional reconstruction of a micro-CT-imaged human ACP sample, in which the glial reactive tissue has not been rendered. Purple indicates the stellate reticulum and cells of the palisading epithelium, and green represents the $\beta$-catenin-accumulating cell clusters. Note the presence of finger-like protrusions of tumour cells, which project away from a tumour epithelium mass, containing a string of clusters inside. These human clusters are molecularly analogous to the mouse clusters and share a signature of senescence and SASP. The model proposes that the SASP activities underlie tumour growth and invasive behaviour by promoting epithelial remodelling and proliferation. 
inhibitor) and cobimetinib (a MEK inhibitor) (ClinicalTrials.gov Identifier: NCT03224767).

In ACP tumours, however, the identification of CTNNB1 mutations leading to the activation of the WNT/ $\beta$-catenin pathway has not been translated into novel targeted treatments due to the difficulty in targeting this pathway without causing unacceptable toxicity. Howevpathways downstream of the WNT/ $\beta$-catenin pathway. Inflammatory mediators (e.g., IL-6 and IL-1) have been identified both in the solid and cystic tumour compartments, suggesting a critical role of these factors in ACP pathogenesis [14, 42, 43]. Supporting this hypothesis, 2 patients have been treated with tocilizumab, an IL-6 inhibitor, leading to a discreet improvement in disease management [44]. Sonic hedgehog, a signalling factor with critical roles during development, was found to be upregulated in mouse and human ACP [45] and further tors, including vismodegib, a clinically approved drug that is used against other human cancers (e.g., medulloblastoma). Unfortunately, pre-clinical data in vitro and in the ACP mouse model as well as patient-derived xenograft mice have shown that vismodegib treatment leads to increased tumour cell proliferation, premature tumouri-

A recent study has revealed that the MAPK/ERK pathway is activated in human and mouse ACP tumours, as evidenced by the expression of p-ERK1/2 [14]. Since ACPs do not carry mutations in MAPK pathway components, these data suggest that the pathway is activated in a paracrine manner. Indeed, cluster cells express many ligands known to signal through this pathway, such as fibroblast growth factors, epithelial growth factors, and platelet-derived growth factors $[14,45]$. Interestingly, the inhibition of the MAPK/ERK pathway using the MEK inhibitor trametinib has been shown to result in reduced proliferation and increased apoptosis in both mouse and human ACP tumours in vitro [14]. There is currently an open clinical trial of single-agent tocilizumab (IL-6R inhibitor; ClinicalTrials.gov \# NCT03970226), and other multicentre trials are in development.

\section{Conclusion}

ACPs and PCPs are relatively simple tumours carrying mutations in either CTNNB1 or BRAF ( $p . B R A F-V 600 E$ ), respectively. At the cellular level, senescence has been er, gene profiling has revealed other potential targetable confirmed in other studies $[14,31,43,46]$. The activation of the SHH pathway can be targeted with several inhibigenesis, and reduced mouse survival [47].

identified as a potentially pro-tumourigenic mechanism that may initiate ACP tumourigenesis in mice and promote growth and invasion in human ACP. The accumulated knowledge on the biology of these tumours is being translated into clinical and pre-clinical trials testing novel targeted therapies. It is likely these studies will provide efficacious medical treatments against these aggressive tumours.

\section{Acknowledgement}

The authors wish to thank Drs Scott Haston, Romain Guiho, and Gabriela Carreno for their help with the Figures.

\section{Statement of Ethics}

Ethical approval was not required since this paper does not concern animal experimentation or the use of human volunteers.

\section{Disclosure Statement}

The authors have no conflicts of interest to declare.

\section{Funding Sources}

Funding for this research was provided by Cancer Research UK, Children's Cancer and Leukaemia Group, Children with Cancer UK (15/190), MRC (MR/M125/1 and MR/L016729/1), Brain Tumour Charity (SIGNAL and EVEREST), Great Ormond Street Hospital Children's Charity, the Lister Institute of Preventive Medicine, the Morgan Adams Foundation and National Institute of Health Research Biomedical Research Centre at the Great Ormond Street Hospital for Children NHS Foundation Trust, and the University College London. J.P.M.-B. is a Great Ormond Street Hospital for Children's Charity Principal Investigator.

\section{Author Contributions}

This paper was written by both authors.

\section{References}

1 Pascual JM, Rosdolsky M, Prieto R, Strau $\beta$ S, Winter E, Ulrich W. Jakob Erdheim (18741937): father of hypophyseal-duct tumors (craniopharyngiomas). Virchows Arch. 2015

2 Erdheim J. Über Hypophysenganggeschwulste und Hirmcholesteatome. Sitzungsb Kais Akad Wiss Math Naturw Klin Padiatr. 1904. 113:537-726. Oct;467(4):459-69. 
3 Apps JR, Hutchinson JC, Shelmerdine S, Virasami A, Winter E, Jacques TS, et al. Learning from cases: Analysis of two cases of craniopharyngioma from the 19th to the 21st centuries. F1000Res. 2019 Aug 30;8:1544.

4 Müller HL, Merchant TE, Warmuth-Metz M, Martinez-Barbera JP, Puget S. Craniopharyngioma. Nat Rev Dis Primers. 2019 Nov;5(1): 75.

5 Karavitaki N, Brufani C, Warner JT, Adams CB, Richards P, Ansorge O, et al. Craniopharyngiomas in children and adults: systematic analysis of 121 cases with long-term followup. Clin Endocrinol (Oxf). 2005 Apr;62(4): 397-409.

6 Robinson LC, Santagata S, Hankinson TC. Potential evolution of neurosurgical treatment paradigms for craniopharyngioma based on genomic and transcriptomic characteristics. Neurosurg Focus. 2016 Dec; 41(6): E3.

7 Alexandraki KI, Kaltsas GA, Karavitaki N, Grossman AB. The Medical Therapy of Craniopharyngiomas: The Way Ahead. J Clin Endocrinol Metab. 2019 Dec;104(12):5751-64.

8 Buchfelder M, Schlaffer SM, Lin F, Kleindienst A. Surgery for craniopharyngioma. Pituitary. 2013 Mar;16(1):18-25.

9 Indelicato DJ, Merchant T, Laperriere N, Lassen Y, Vennarini S, Wolden S, et al. Consensus Report from the Stockholm Pediatric Proton Therapy Conference. Int J Radiat Oncol Biol Phys. 2016 Oct;96(2):387-92.

10 Puget S. Treatment strategies in childhood craniopharyngioma. Front Endocrinol (Lausanne). 2012 Jun;3:64.

11 Liu Y, Qi ST, Wang CH, Pan J, Fan J, Peng JX, et al. Pathological Relationship between Adamantinomatous Craniopharyngioma and Adjacent Structures Based on QST Classification. J Neuropathol Exp Neurol. 2018 Nov; 77(11):1017-23.

12 Martinez-Barbera JP, Buslei R. Adamantinomatous craniopharyngioma: pathology, molecular genetics and mouse models. J Pediatr Endocrinol Metab. 2015 Jan;28(1-2):7-17.

13 Apps JR, Hutchinson JC, Arthurs OJ, Virasami A, Joshi A, Zeller-Plumhoff B, et al. Imaging Invasion: Micro-CT imaging of adamantinomatous craniopharyngioma highlights cell type specific spatial relationships of tissue invasion. Acta Neuropathol Commun. 2016 Jun;4(1):57.

14 Apps JR, Carreno G, Gonzalez-Meljem JM, Haston S, Guiho R, Cooper JE, et al. Tumour compartment transcriptomics demonstrate the activation of inflammatory and odontogenic programmes in human adamantinomatous craniopharyngioma and identifies the MAPK/ERK pathway as a novel therapeutic target. Acta Neuropathol. 2018;135(5):75577.

15 Sekine S, Shibata T, Kokubu A, Morishita Y, Noguchi M, Nakanishi Y, et al. Craniopharyngiomas of adamantinomatous type harbor beta-catenin gene mutations. Am J Pathol. 2002 Dec;161(6):1997-2001.
16 Martinez-Barbera JP. 60 YEARS OF NEUROENDOCRINOLOGY: Biology of human craniopharyngioma: lessons from mouse models. J Endocrinol. 2015 Aug;226(2):T161-72.

17 Buslei R, Nolde M, Hofmann B, Meissner S, Eyupoglu IY, Siebzehnrübl F, et al. Common mutations of beta-catenin in adamantinomatous craniopharyngiomas but not in other tumours originating from the sellar region. Acta Neuropathol. 2005 Jun;109(6):589-97.

18 Larkin SJ, Preda V, Karavitaki N, Grossman A, Ansorge O. BRAF V600E mutations are characteristic for papillary craniopharyngioma and may coexist with CTNNB1-mutated adamantinomatous craniopharyngioma. Acta Neuropathol. 2014;127(6):927-9.

19 Kato K, Nakatani Y, Kanno H, Inayama Y, Ijiri R, Nagahara N, et al. Possible linkage between specific histological structures and aberrant reactivation of the Wnt pathway in adamantinomatous craniopharyngioma. J Pathol. 2004 Jul;203(3):814-21.

20 Hölsken A, Kreutzer J, Hofmann BM, Hans V, Oppel F, Buchfelder M, et al. Target gene activation of the Wnt signaling pathway in nuclear beta-catenin accumulating cells of adamantinomatous craniopharyngiomas. Brain Pathol. 2009 Jul;19(3):357-64.

21 Apps JR, Stache C, Gonzalez-Meljem JM, Gutteridge A, Chalker J, Jacques TS, et al. CTNNB1 mutations are clonal in adamantinomatous craniopharyngioma. Neuropathol Appl Neurobiol. 2020. DOI: 10.1111/nan. 12613.

22 Andoniadou CL, Matsushima D, Mousavy Gharavy SN, Signore M, Mackintosh AI, Schaeffer M, et al. Sox2(+) stem/progenitor cells in the adult mouse pituitary support organ homeostasis and have tumor-inducing potential. Cell Stem Cell. 2013 Oct;13(4):43345.

23 Gaston-Massuet C, Andoniadou CL, Signore M, Jayakody SA, Charolidi N, Kyeyune R, et al. Increased Wingless (Wnt) signaling in pituitary progenitor/stem cells gives rise to pituitary tumors in mice and humans. Proc Natl Acad Sci USA. 2011 Jul;108(28):11482-7.

24 Boult JKR, Apps JR, Hölsken A, Hutchinson JC, Carreno G, Danielson LS, et al. Preclinical transgenic and patient-derived xenograft models recapitulate the radiological features of human adamantinomatous craniopharyngioma. Brain Pathol. 2018 Jul;28(4):475-483.

25 Buslei R, Hölsken A, Hofmann B, Kreutzer J, Siebzehnrubl F, Hans V, et al. Nuclear betacatenin accumulation associates with epithelial morphogenesis in craniopharyngiomas. Acta Neuropathol. 2007 May;113(5):585-90.

26 Hofmann BM, Kreutzer J, Saeger W, Buchfelder M, Blümcke I, Fahlbusch R, et al. Nuclear beta-catenin accumulation as reliable marker for the differentiation between cystic craniopharyngiomas and rathke cleft cysts: a clinico-pathologic approach. Am J Surg Pathol. 2006 Dec;30(12):1595-603.
27 Paulus W, Stöckel C, Krauss J, Sörensen N, Roggendorf W. Odontogenic classification of craniopharyngiomas: a clinicopathological study of 54 cases. Histopathology. 1997 Feb; 30(2):172-6.

28 Brastianos PK, Taylor-Weiner A, Manley PE, Jones RT, Dias-Santagata D, Thorner AR, et al. Exome sequencing identifies BRAF mutations in papillary craniopharyngiomas. Nat Genet. 2014 Feb;46(2):161-5.

29 Goschzik T, Gessi M, Dreschmann V, Gebhardt U, Wang L, Yamaguchi S, et al. Genomic Alterations of Adamantinomatous and Papillary Craniopharyngioma. J Neuropathol Exp Neurol. 2017 Feb;76(2):126-34.

30 Capper D, Jones DT, Sill M, Hovestadt V, Schrimpf D, Sturm D, et al. DNA methylation-based classification of central nervous system tumours. Nature. 2018 Mar;555(7697): 469-74.

31 Hölsken A, Sill M, Merkle J, Schweizer L, Buchfelder M, Flitsch J, et al. Adamantinomatous and papillary craniopharyngiomas are characterized by distinct epigenomic as well as mutational and transcriptomic profiles. Acta Neuropathol Commun. 2016 Feb;4(1) 20.

32 Haston S, Pozzi S, Carreno G, Manshaei S, Panousopoulos L, Gonzalez-Meljem JM, et al MAPK pathway control of stem cell proliferation and differentiation in the embryonic pituitary provides insights into the pathogenesis of papillary craniopharyngioma. Development. 2017 Jun; 144(12):2141-52.

33 Tchkonia T, Zhu Y, van Deursen J, Campisi J, Kirkland JL. Cellular senescence and the senescent secretory phenotype: therapeutic opportunities. J Clin Invest. 2013 Mar;123(3): 966-72.

34 McHugh D, Gil J. Senescence and aging: Causes, consequences, and therapeutic avenues. J Cell Biol. 2018 Jan;217(1):65-77.

35 Coppé JP, Desprez PY, Krtolica A, Campisi J. The senescence-associated secretory phenotype: the dark side of tumor suppression. Annu Rev Pathol. 2010;5(1):99-118.

36 Childs BG, Gluscevic M, Baker DJ, Laberge RM, Marquess D, Dananberg J, et al. Senescent cells: an emerging target for diseases of ageing. Nat Rev Drug Discov. 2017 Oct; 16(10):718-35.

37 Gonzalez-Meljem JM, Apps JR, Fraser HC, Martinez-Barbera JP. Paracrine roles of cellular senescence in promoting tumourigenesis. Br J Cancer. 2018 May;118(10):1283-8.

38 Gonzalez-Meljem JM, Martinez-Barbera JP. Senescence drives non-cell autonomous tumorigenesis in the pituitary gland. Mol Cell Oncol. 2018 Feb;5(3):e1435180.

39 Gonzalez-Meljem JM, Haston S, Carreno G, Apps JR, Pozzi S, Stache C, et al. Stem cell senescence drives age-attenuated induction of pituitary tumours in mouse models of paediatric craniopharyngioma. Nat Commun. 2017 Nov;8(1):1819. 
40 Brastianos PK, Shankar GM, Gill CM, TaylorWeiner A, Nayyar N, Panka DJ, et al. Dramatic Response of BRAF V600E Mutant Papillary Craniopharyngioma to Targeted Therapy. J Natl Cancer Inst. 2015 Oct;108(2): djv310.

41 Aylwin SJ, Bodi I, Beaney R. Pronounced response of papillary craniopharyngioma to treatment with vemurafenib, a BRAF inhibitor. Pituitary. 2016 Oct;19(5):544-6.

42 Donson AM, Apps J, Griesinger AM, Amani V, Witt DA, Anderson RC, et al.; Advancing Treatment for Pediatric Craniopharyngioma Consortium. Molecular Analyses Reveal Inflammatory Mediators in the Solid Compo- nent and Cyst Fluid of Human Adamantinomatous Craniopharyngioma. J Neuropathol Exp Neurol. 2017 Sep;76(9):779-88.

43 Gump JM, Donson AM, Birks DK, Amani VM, Rao KK, Griesinger AM, et al. Identification of targets for rational pharmacological therapy in childhood craniopharyngioma. Acta Neuropathol Commun. 2015 May;3(1):30.

44 Grob S, Mirsky DM, Donson AM, Dahl N, Foreman NK, Hoffman LM, et al. Targeting IL-6 Is a Potential Treatment for Primary Cystic Craniopharyngioma. Front Oncol. 2019 Aug;9:791.

45 Andoniadou CL, Gaston-Massuet C, Reddy R, Schneider RP, Blasco MA, Le Tissier P, et al. Identification of novel pathways involved in the pathogenesis of human adamantinomatous craniopharyngioma. Acta Neuropathol. 2012 Aug;124(2):259-71.

46 Gomes DC, Jamra SA, Leal LF, Colli LM, Campanini ML, Oliveira RS, et al. Sonic Hedgehog pathway is upregulated in adamantinomatous craniopharyngiomas. Eur J Endocrinol. 2015 May;172(5):603-8.

47 Carreno G, Boult JK, Apps J, GonzalezMeljem JM, Haston S, Guiho R, et al. SHH pathway inhibition is protumourigenic in adamantinomatous craniopharyngioma. Endocr Relat Cancer. 2019 Mar;26(3):35566. 